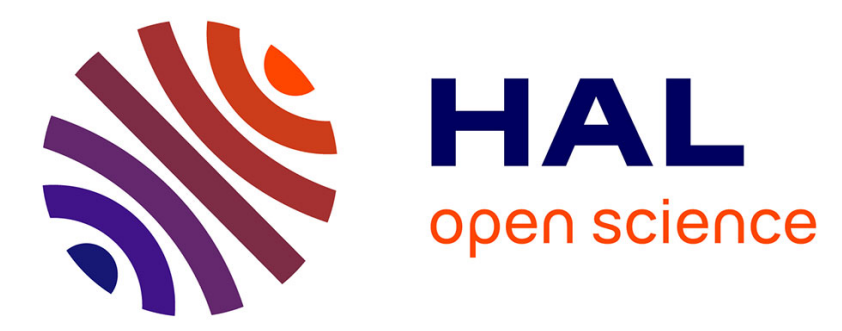

\title{
Colloidal suspensions of highly luminescent lanthanide-based coordination polymer molecular alloys for ink-jet printing and tagging of technical liquids
}

Youenn Pointel, Carole Daiguebonne, Yan Suffren, Francois Le Natur, Stéphane Freslon, Guillaume Calvez, Kevin Bernot, David Jacob, Olivier Guillou

\section{To cite this version:}

Youenn Pointel, Carole Daiguebonne, Yan Suffren, Francois Le Natur, Stéphane Freslon, et al.. Colloidal suspensions of highly luminescent lanthanide-based coordination polymer molecular alloys for ink-jet printing and tagging of technical liquids. Inorganic Chemistry Frontiers, 2021, 8 (8), pp.21252135. 10.1039/d1qi00060h . hal-03245099

\author{
HAL Id: hal-03245099 \\ https://hal.science/hal-03245099
}

Submitted on 23 Jun 2021

HAL is a multi-disciplinary open access archive for the deposit and dissemination of scientific research documents, whether they are published or not. The documents may come from teaching and research institutions in France or abroad, or from public or private research centers.
L'archive ouverte pluridisciplinaire HAL, est destinée au dépôt et à la diffusion de documents scientifiques de niveau recherche, publiés ou non, émanant des établissements d'enseignement et de recherche français ou étrangers, des laboratoires publics ou privés. 


\title{
Colloidal suspensions of highly luminescent
}

\author{
lanthanide-based \\ coordination \\ polymers
}

\section{molecular alloys for ink-jet printing and tagging}

\section{of technical liquids.}

Youenn Pointel ${ }^{\mathrm{a}, \mathrm{b}, \mathrm{c}}$, Carole Daiguebonne ${ }^{\mathrm{a}, \mathrm{c}}$, Yan Suffren ${ }^{\mathrm{a}, \mathrm{c}, *}$, Francois Le Natur ${ }^{\mathrm{b}, \mathrm{c}}$, Stéphane Freslon ${ }^{\mathrm{a}, \mathrm{c}}$, Guillaume Calvez ${ }^{\mathrm{a}, \mathrm{c}}$, Kevin Bernot $^{\mathrm{a}, \mathrm{c}, \mathrm{d}}$, David Jacob ${ }^{\mathrm{e}}$ and Olivier Guillou ${ }^{\mathrm{a}, \mathrm{c}}$.

${ }^{a}$ Univ Rennes, INSA Rennes, CNRS UMR 6226 "Institut des Sciences Chimiques de Rennes", F-35708 Rennes, France.

${ }^{\mathrm{b}}$ Olnica, 40 Rue du Bignon, F-35135 Chantepie, France.

${ }^{\mathrm{c}}$ ChemInTag, INSA Rennes, Olnica, F-35708 Rennes, France.

${ }^{\mathrm{d}}$ Institut Universitaire de France (IUF) 1 rue Descartes, F-75231 Paris, France.

${ }^{e}$ Cordouan Technologies, Cité de la photonique, Bât Pleione, 11 Avenue de Canteranne, 33600 PESSAC, France.

* To whom correspondence should be addressed: Yan.Suffren@ insa-rennes.fr 


\begin{abstract}
.
Highly luminescent and color-tunable stable colloidal suspensions of molecular alloys are reported. They are produced via a green synthetic route in ethanol medium. The mean hydrodynamic diameter of the colloids is about $140 \mathrm{~nm}$ and the colloidal suspensions are stable for more than a month. The optical properties of the molecular alloys suspensions and of their bulk counterparts are extremely similar. To the best of our knowledge, this series of suspensions constitutes the first example of hetero-lanthanide coordination polymers molecular alloys (LnCPMAs)-based colloidal suspensions with sizeable luminescence intensity and a wide range of accessible colors. This high color tunability paves the road toward tagging of technical liquids. We also demonstrate that they can be used in ink-jet printers for luminescent anti-counterfeiting tagging.
\end{abstract}




\section{INTRODUCTION.}

Lanthanide-based coordination compounds attract a growing interest because of their unique optical properties. ${ }^{1-5}$ Indeed, they can find their application in various fields such as thermometry, ${ }^{6-7}$ light and display ${ }^{8-9}$, sensing ${ }^{10-11}$ or fight against counterfeiting. ${ }^{12-14}$ For more than a decade, it has been demonstrated that hetero-lanthanide-based coordination polymers ${ }^{15}$ (CP), also called "molecular alloys", ${ }^{16}$ are excellent taggants for fight against counterfeiting because they constitute very large series of iso-structural compounds with highly tunable luminescence and brightness. ${ }^{17-20}$

However, CPs are most often insoluble which makes difficult their use in the liquid-state. Several technics have been explored to prepare nanometric grains of coordination polymers suitable for dispersion in a liquid medium. ${ }^{21-22}$ In this frame, microwave and ultrasonic assisted irradiations used as non-conventional heating procedures have demonstrated their efficiency for reducing the size of the crystallites for inorganic compounds and these technics could be extended to coordination polymers. ${ }^{23-24}$ Post-synthetic treatment such as suspension in ionic liquids ${ }^{25}$ or poly-alcohols ${ }^{26}$ have also been successfully used as well as encapsulation of the coordination polymer by an organic polymer ${ }^{27-28}$ or a surfactant ${ }^{29}$. However, all these technics present serious drawbacks such as uncontrolled purity, solvent toxicity or cost of the dissolution process. Moreover, when nanometric homo-metallic lanthanides-based coordination polymers or complexes are used for luminescent inkjet printing applications $^{30,14,31}$ they rely on the mixing of blue, red and green emitting species that are prepared and stored independently. Consequently, the final dried solid is a mixture of blue, red and green emitting nanocrystals without energy transfers between them.

Therefore, it is clear that the design of compounds with identical, sizeable and tunable optical fingerprints in the solid- and in the liquid-states is a lock toward elaborated luminescent tagging of technical liquids. In this work, we report that a specific family of lanthanide-based 
coordination polymers molecular alloys (Ln-CPMAs) is adapted to that purpose. Indeed, recently Ln-CPMAs iso-structural with $\left[\mathrm{Eu}_{2}(\mathrm{dcpa})_{3}\left(\mathrm{H}_{2} \mathrm{O}\right)\right]_{\infty}{ }^{31-32}$ (where $\mathrm{H}_{2} \mathrm{dcpa}$ stands for 4,5-dichlorophthalic acid) have been reported. ${ }^{33-34}$ Their synthesis is respectful of environment (synthesis is performed in water under ambient temperature and pressure in high yields) ${ }^{35}$ and some of these Ln-CPMAs exhibit excellent brightness. They also form a very large series of compounds which allows a wide emission color modulation. Moreover, microcrystalline powders of these compounds are made of nanometric grains of quite homogenous size (some tens of nanometers) (Figure 1) which constitutes a key as far as colloidal dispersions are targeted.

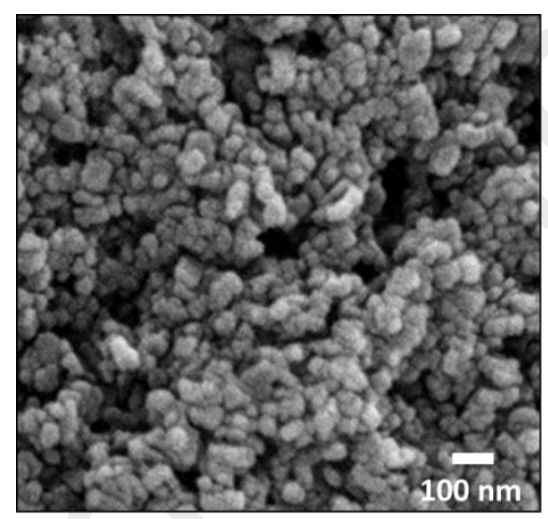

Figure 1. SEM picture of a microcrystalline powder of $\left[\mathrm{Eu}_{0.2} \mathrm{La}_{1.8}(\mathrm{dcpa})_{3}\left(\mathrm{H}_{2} \mathrm{O}\right)\right]_{\infty}$.

In this paper, we report how a family of luminescent Ln-CPMAs can be solubilized and we demonstrate how their bulk luminescent properties are preserved in their colloidal suspensions counterparts.

\section{EXPERIMENTAL SECTION.}

Powder X-ray diffraction, Electron Dispersive Spectroscopy (EDS) measurement and optical and colorimetric measurements have been performed according to procedures that have already been described. ${ }^{36}$ They are reported in the Supporting Information Section. 


\section{Preparation of the solid samples.}

Microcrystalline powders of the homo- and hetero-lanthanide coordination polymers have been prepared according to the procedure that has already been described. ${ }^{34}$

Iso-structurality of the prepared compounds with $\left[\mathrm{Eu}_{2}(\mathrm{dcpa})_{3}\left(\mathrm{H}_{2} \mathrm{O}\right)\right]_{\infty}{ }^{31-32}$ (where $\mathrm{H}_{2}$ dcpa stands for 4,5-dichlorophthalic acid) has been assumed on the basis of their powder X-ray diffraction patterns. Because this iso-structurality has already been demonstrated recently, ${ }^{33-34}$ only the powder X-ray diffraction diagram of $\left[\operatorname{Eu}_{0.2} \mathrm{La}_{1.8}(\mathrm{dcpa})_{3}\left(\mathrm{H}_{2} \mathrm{O}\right)\right]_{\infty}$ is reported (Table S1 and Figure S1) as a matter of example. Relative contents of the different lanthanide ions in hetero-lanthanide compounds have been determined by EDS measurements. Homogeneity of the powders has been assumed on the basis of multiple EDS measurements performed on several samples.

\section{Chemical stability.}

Powders of $\left[\mathrm{Tb}_{0.2} \mathrm{La}_{1.8}(\mathrm{dcpa})_{3}\left(\mathrm{H}_{2} \mathrm{O}\right)\right]_{\infty}$ (Table S2) have been suspended (30 mg in $30 \mathrm{~mL}$ ) in different commonly used industrial solvents (ethyl-acetate, propan-2-one, acetonitrile, butanone, chloroform, dichloro-methane, ethanol, diethyl-ether, methanol, tetrahydrofuran and toluene) as well as in acidic and basic aqueous solutions. Suspensions have been maintained under vigorous stirring for two days. Then, emission spectra of the suspensions $\left(\lambda_{\mathrm{exc}}=303 \mathrm{~nm}\right)$ have been recorded (Figures S2 and S4). At last, suspensions have been evaporated to dryness and their powder X-ray diffraction patterns have been collected (Figure S3 and S5).

These experiments strongly suggest that the coordination polymers are stable in aqueous solutions with $\mathrm{pH}$ values comprised between 4 and 11. Below 4, the ligand is protonated and then coordination vanishes and above 11, lanthanide hydroxide is formed. 
All the suspensions (except those realized in ketones) emit under $303 \mathrm{~nm}$ excitation wavelength which indicates that the ligands are coordinated to the lanthanide ions in organic suspensions. The fact that ketone suspensions don't emit has already been observed and attributed to the large $\pi^{*} \leftarrow \mathrm{n}$ absorption band of the solvent (230-325 nm) that quenches the luminescence of the coordination polymer. ${ }^{37}$ Powder X-ray diffraction patterns show that all the solids obtained after evaporation of the solvents are iso-structural to $\left[\mathrm{Eu}_{2}(\mathrm{dcpa})_{3}\left(\mathrm{H}_{2} \mathrm{O}\right)\right]_{\infty}$. These experiments strongly suggest that the coordination polymer doesn't collapse in any tested organic solvent.

\section{Preparation of suspensions in ethanol.}

Suspensions in ethanol $\left(0.3\right.$ g.L $\left.\mathrm{L}^{-1}\right)$ have been prepared under sonication. Ethanol has been chosen because water provokes segregation and sedimentation and because ethanol is a commonly used solvent in industrial processes.

\section{Chemical hazards.}

In the frame of this study, nanometric powders have been prepared and then dispersed in ethanol for comparison. It is well known that the manipulation of nanometric powders is not recommended in industrial processes. ${ }^{38}$ However this solid-state step is not mandatory and it is possible to purify and disperse the nanoparticles by a cycle of rinses/centrifugations without drying. This procedure makes the synthetic process safe and easily up-scalable.

\section{DLS Measurements.}

Particle size measurements of the suspension have been achieved with the VASCO Kin $^{\mathrm{TM}}$ DLS system from Cordouan technologies equipped with an in situ contactless fiber remote probe. The backscattered light is detected with an angle of $170^{\circ}$. The laser wavelength 
is $638 \mathrm{~nm}$. Samples have been measured at ambient temperature. The hydrodynamic diameter (Zaverage) and distribution width (PDI) have been determined from the Cumulants inversion method.

\section{RESULTS AND DISCUSSION.}

Reaction in water at ambient temperature and pressure, between a lanthanide ion (or a mixture of lanthanide ions) aqueous solution with the di-sodium salt of 4,5-dichlorophthalic acid $\left(\mathrm{H}_{2} \mathrm{dcpa}\right)$ leads to two families of iso-structural compounds depending on the lanthanide ion. The first family gathers the homo-lanthanide coordination polymers obtained with the lightest lanthanide ions ( $\mathrm{La}-\mathrm{Gd}$ except $\mathrm{Pm}$ ) and are iso-structural to $\left[\mathrm{Eu}_{2}(\mathrm{dcpa})_{3}\left(\mathrm{H}_{2} \mathrm{O}\right)\right]_{\infty}$ (Family 1). ${ }^{31-32}$ Compounds that involve the heaviest lanthanide (Tb-Lu) or Y are iso-structural to $\left[\mathrm{Er}_{2}(\mathrm{dcpa})_{3}\left(\mathrm{H}_{2} \mathrm{O}\right)_{5} \cdot 3 \mathrm{H}_{2} \mathrm{O}\right]_{\infty}$ (Family 2$){ }^{36}$

In the solid-state, the crystal structure of the first family provides much more intense luminescence than the one of the second family and it has been demonstrated that phase-induction between these two families is possible. In other words, it is possible to prepare hetero-lanthanide compounds that crystallize in the first structural type $\left(\left[\mathrm{Eu}_{2}(\mathrm{dcpa})_{3}\left(\mathrm{H}_{2} \mathrm{O}\right)\right]_{\infty}\right)$ and contain optically active lanthanide ions that, alone, would lead to the second structural type $\left(\left[\mathrm{Er}_{2}(\mathrm{dcpa})_{3}\left(\mathrm{H}_{2} \mathrm{O}\right)_{5} \cdot 3 \mathrm{H}_{2} \mathrm{O}\right]_{\infty}\right) .{ }^{34}$ This is achieved for hetero-lanthanide molecular alloys that contain a large enough amount of lanthanum, for example. Therefore, in order to obtain a luminescence as intense as possible, we have prepared Ln-CPMAs with high lanthanum contents, that are all isostructural to $\left[\mathrm{Eu}_{2}(\mathrm{dcpa})_{3}\left(\mathrm{H}_{2} \mathrm{O}\right)\right]_{\infty}($ Family 1$)$.

The crystal structure of $\left[\mathrm{Eu}_{2}(\mathrm{dcpa})_{3}\left(\mathrm{H}_{2} \mathrm{O}\right)\right]_{\infty}$ has already been reported $^{31-32}$ (CCDC-1551529). It crystallizes in the monoclinic system, space group $P 2{ }_{1} / c$ (n $\left.{ }^{\circ} 14\right)$. It can be described on the basis of molecular planes that spread parallel to the $(a, c)$ plane. The crystal 
packing is insured by halogen-bonds between the chloride ions that point toward the inter-planes space (Figure 2).

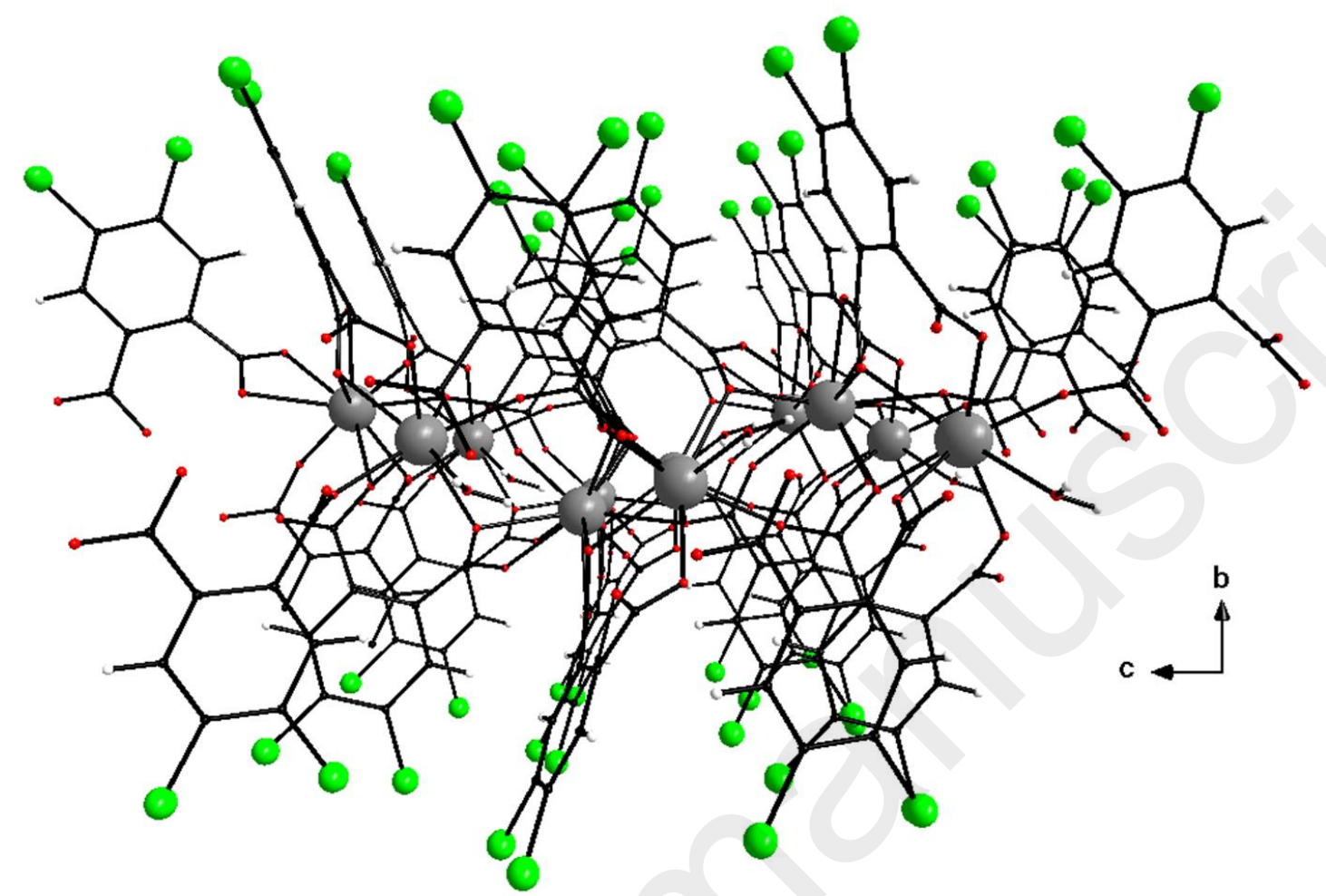

Figure 2. Perspective view, along the $a$-axis of a molecular layer of $\left[\mathrm{Eu}_{2}(\mathrm{dcpa})_{3}\left(\mathrm{H}_{2} \mathrm{O}\right)\right]_{\infty}$. Chloride atoms are in green. Redrawn from reference 31.

Integrity of the crystallites in ethanolic solutions: comparison of luminescent Ln-CPMAs.

In order to confirm the stability of the molecular framework when the microcrystalline powder is immersed in ethanol, four suspensions of Ln-CPMAs in ethanol have been prepared (Table S3): $\left[\mathrm{TbLa}(\mathrm{dcpa})_{3}\left(\mathrm{H}_{2} \mathrm{O}\right)\right]_{\infty}: \mathrm{EtOH}\left(\mathbf{O}\right.$ and $\left[\mathrm{EuLa}(\mathrm{dcpa})_{3}\left(\mathrm{H}_{2} \mathrm{O}\right)\right]_{\infty}: \mathrm{EtOH}$ 2, the equimolar mixture of both $\left(0.5\left[\mathrm{EuLa}(\mathrm{dcpa})_{3}\left(\mathrm{H}_{2} \mathrm{O}\right)\right]_{\infty}+0.5\left[\mathrm{TbLa}(\mathrm{dcpa})_{3}\left(\mathrm{H}_{2} \mathrm{O}\right)\right]_{\infty}\right):$ EtOH 3 and the corresponding tri-lanthanide compound $\left[\mathrm{Eu}_{0.5} \mathrm{~Tb}_{0.5} \mathrm{La}(\mathrm{dcpa})_{3}\left(\mathrm{H}_{2} \mathrm{O}\right)\right]_{\infty}: \mathrm{EtOH}$ 4. This composition is chosen because sizeable Tb-to-Eu intermetallic energy transfers are observed in the solid-state for this $\mathrm{Tb} / \mathrm{Eu}$ ratio. ${ }^{34}$ 
All the compounds are iso-structural to $\left[\mathrm{Eu}_{2}(\mathrm{dcpa})_{3}\left(\mathrm{H}_{2} \mathrm{O}\right)\right]_{\infty}$. Colorimetric coordinates and emission spectra of the four compounds have been measured after dispersion in ethanol (in the liquid-state) (Figure 3).
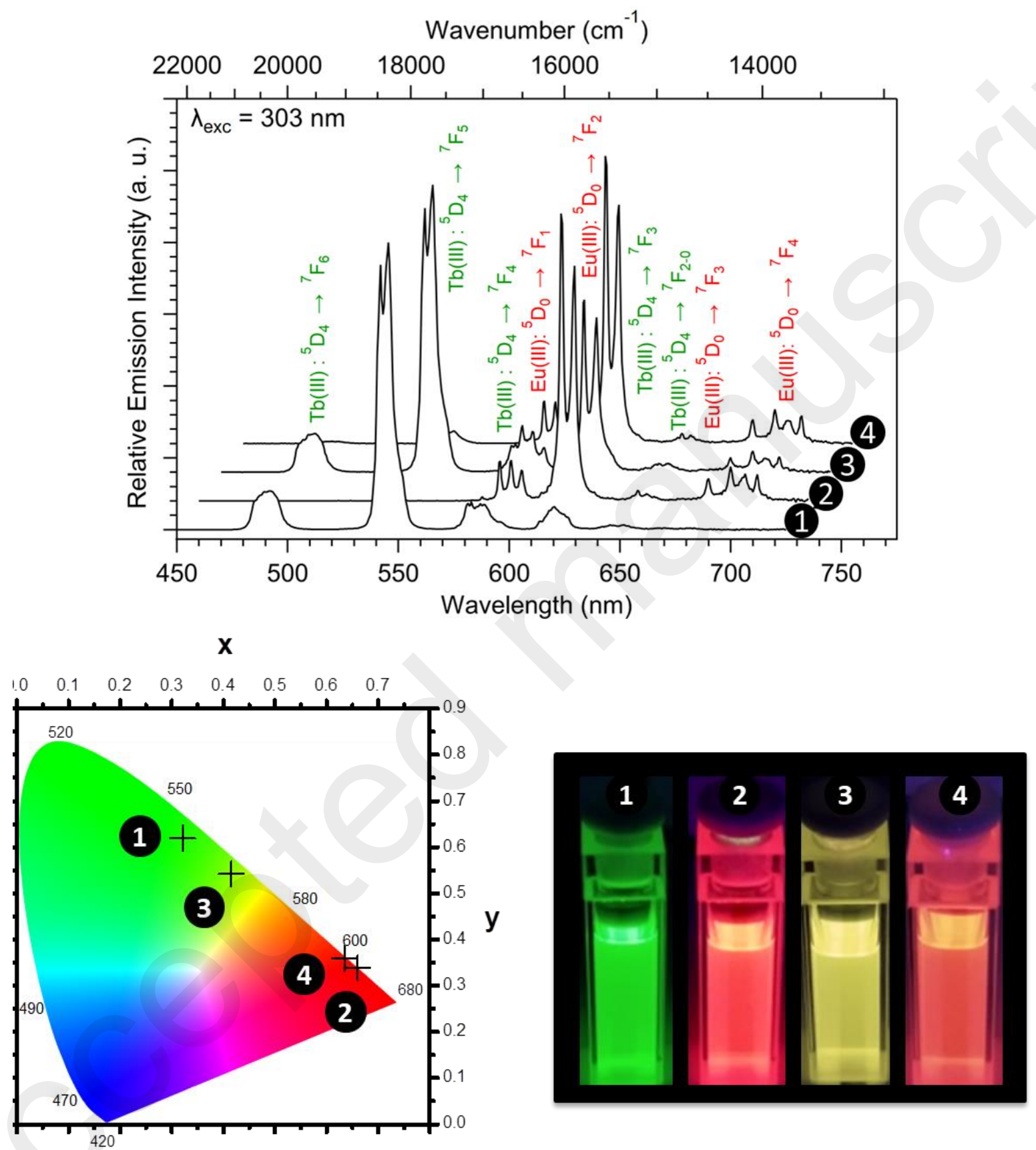

Figure 3. Emission spectra $\left(\lambda_{\mathrm{exc}}=303 \mathrm{~nm}\right)$ (top), colorimetric coordinates $\left(\lambda_{\mathrm{exc}}=303 \mathrm{~nm}\right)$ (bottom left) and picture under UV irradiation $\left(\lambda_{\text {exc }}=312 \mathrm{~nm}\right)$ (bottom right) of $\left[\mathrm{TbLa}(\mathrm{dcpa})_{3}\left(\mathrm{H}_{2} \mathrm{O}\right)\right]_{\infty}: \mathrm{EtOH} \mathbf{O},\left[\mathrm{EuLa}(\mathrm{dcpa})_{3}\left(\mathrm{H}_{2} \mathrm{O}\right)\right]_{\infty}: \mathrm{EtOH}$ 2, $\left(0.5\left[\mathrm{EuLa}(\mathrm{dcpa})_{3}\left(\mathrm{H}_{2} \mathrm{O}\right)\right]_{\infty}+\right.$ $\left.0.5\left[\mathrm{TbLa}(\mathrm{dcpa})_{3}\left(\mathrm{H}_{2} \mathrm{O}\right)\right]_{\infty}\right): \mathrm{EtOH} 3$ and $\left[\mathrm{Eu}_{0.5} \mathrm{~Tb}_{0.5} \mathrm{La}(\mathrm{dcpa})_{3}\left(\mathrm{H}_{2} \mathrm{O}\right)\right]_{\infty}: \mathrm{EtOH} 4$ suspensions. 
Figure 3 strongly suggests that the molecular structure of the Ln-CPMAs is not destroyed upon suspension in ethanol. First, the equimolar mixture of $\left[\mathrm{EuLa}(\mathrm{dcpa})_{3}\left(\mathrm{H}_{2} \mathrm{O}\right)\right]_{\infty}$ and $\left[\mathrm{TbLa}(\mathrm{dcpa})_{3}\left(\mathrm{H}_{2} \mathrm{O}\right)\right]_{\infty}(3)$ is dominated by the green emission of the Tb-derivatives which is in agreement with its brighter luminescence observed in the solid-state when compared with that of the Eu-derivative. ${ }^{34}$ Second, the emission of $\left[\mathrm{Eu}_{0.5} \mathrm{~Tb}_{0.5} \mathrm{La}(\mathrm{dcpa})_{3}\left(\mathrm{H}_{2} \mathrm{O}\right)\right]_{\infty}: \mathrm{EtOH}(\mathbf{4})$ is dominated by the red luminescence of the $\mathrm{Eu}^{3+}$ ions which is in agreement with $\mathrm{Tb}$-to-Eu inter-metallic energy transfers observed in the solid-state. ${ }^{34}$ Last, all the compounds present sizeable emission upon $303 \mathrm{~nm}$ excitation wavelength which indicates an efficient "antenna effect" $^{\text {39 }}$ and therefore a coordination of the lanthanide ions by the ligand.

Preservation of the bulk emission color in colloidal solutions: investigation of a family of Ln-CPMAs with one emitting Ln ion

In order to compare the luminescence in the solid-state and in the liquid-state, a series of Ln-CPMAs of formula $\left[\mathrm{Ln}_{0.2} \mathrm{La}_{1.8}(\mathrm{dcpa})_{3}\left(\mathrm{H}_{2} \mathrm{O}\right)\right]_{\infty}$ with $\mathrm{Ln}=\mathrm{Sm}, \mathrm{Eu}$, Tb and Dy has been prepared (Table S4). Because of the high lanthanum content, all of them are iso-structural to $\left[\mathrm{Eu}_{2}(\mathrm{dcpa})_{3}\left(\mathrm{H}_{2} \mathrm{O}\right)\right]_{\infty}$. Their luminescence and colorimetric properties have been measured in the solid-state (before dispersion in ethanol) and in the liquid state (after dispersion in ethanol at 0.3g.L $\mathrm{L}^{-1}$ ) (Figure 4 and Table 1). 
Table 1. Overall quantum yields, luminescence lifetimes, luminance and colorimetric coordinates of $\left[\mathrm{Ln}_{0.2} \mathrm{La}_{1.8}(\mathrm{dcpa})_{3}\left(\mathrm{H}_{2} \mathrm{O}\right)\right]_{\infty}$ and $\left[\mathrm{Ln}_{0.2} \mathrm{La}_{1.8}(\mathrm{dcpa})_{3}\left(\mathrm{H}_{2} \mathrm{O}\right)\right]_{\infty}:$ EtOH $\left(0.3 \mathrm{~g} . \mathrm{L}^{-1}\right)$ with $\mathrm{Ln}=\mathrm{Sm}, \mathrm{Eu}, \mathrm{Tb}$ and $\mathrm{Dy}$

\begin{tabular}{lccccc}
\hline & $\mathrm{Ln}$ & $\begin{array}{c}\mathrm{Q}_{\mathrm{Ln}}^{\mathrm{Ligand}} \\
(\%)^{\mathrm{a}}\end{array}$ & $\begin{array}{c}\tau_{\mathrm{obs}} \\
(\mathrm{ms})^{\mathrm{a}}\end{array}$ & $\begin{array}{c}\text { Luminance } \\
\left(\mathrm{cd} \cdot \mathrm{m}^{-2}\right)^{\mathrm{b}}\end{array}$ & $\begin{array}{c}\text { Colorimetric } \\
\text { coordinates } \\
(\mathrm{x}, \mathrm{y})^{\mathrm{a}}\end{array}$ \\
\hline & $\mathrm{Sm}$ & $3.9(2)$ & $0.50(1)$ & $0.32(5)$ & $(0.60,0.39)$ \\
{$\left[\mathrm{Ln}_{0.2} \mathrm{La}_{1.8}(\mathrm{dcpa})_{3}\left(\mathrm{H}_{2} \mathrm{O}\right)\right]_{\infty}: \mathrm{EtOH}$} & $\mathrm{Eu}$ & $20(1)$ & $1.14(1)$ & $2.5(5)$ & $(0.65,0.34)$ \\
& $\mathrm{Tb}$ & $49(2)$ & $2.41(1)$ & $11.8(10)$ & $(0.32,0.61)$ \\
& $\mathrm{Dy}$ & $5.9(1)$ & $0.39(1)$ & $0.17(3)$ & $(0.42,0.44)$ \\
\hline & $\mathrm{Sm}$ & $9.2(2)$ & $0.38(1)$ & $15(3)$ & $(0.62,0.38)$ \\
{$\left[\mathrm{Ln}_{0.2} \mathrm{La}_{1.8}(\mathrm{dcpa})_{3}\left(\mathrm{H}_{2} \mathrm{O}\right)\right]_{\infty}$} & $\mathrm{Eu}$ & $36.8(5)$ & $1.52(1)$ & $43(4)$ & $(0.66,0.34)$ \\
& $\mathrm{Tb}$ & $78(2)$ & $1.76(2)$ & $225(5)$ & $(0.32,0.62)$ \\
& $\mathrm{Dy}$ & $22.1(3)$ & $0.29(1)$ & $39(4)$ & $(0.43,0.46)$ \\
\hline${ }^{\mathrm{a}} \lambda_{\text {exc }}=303 \mathrm{~nm}$ & & & & & \\
$\mathrm{~b} \lambda_{\mathrm{exc}}=312 \mathrm{~nm}$ flux: $0.75(2) \mathrm{mW} . \mathrm{cm}^{-2}$ & & & & \\
\hline
\end{tabular}
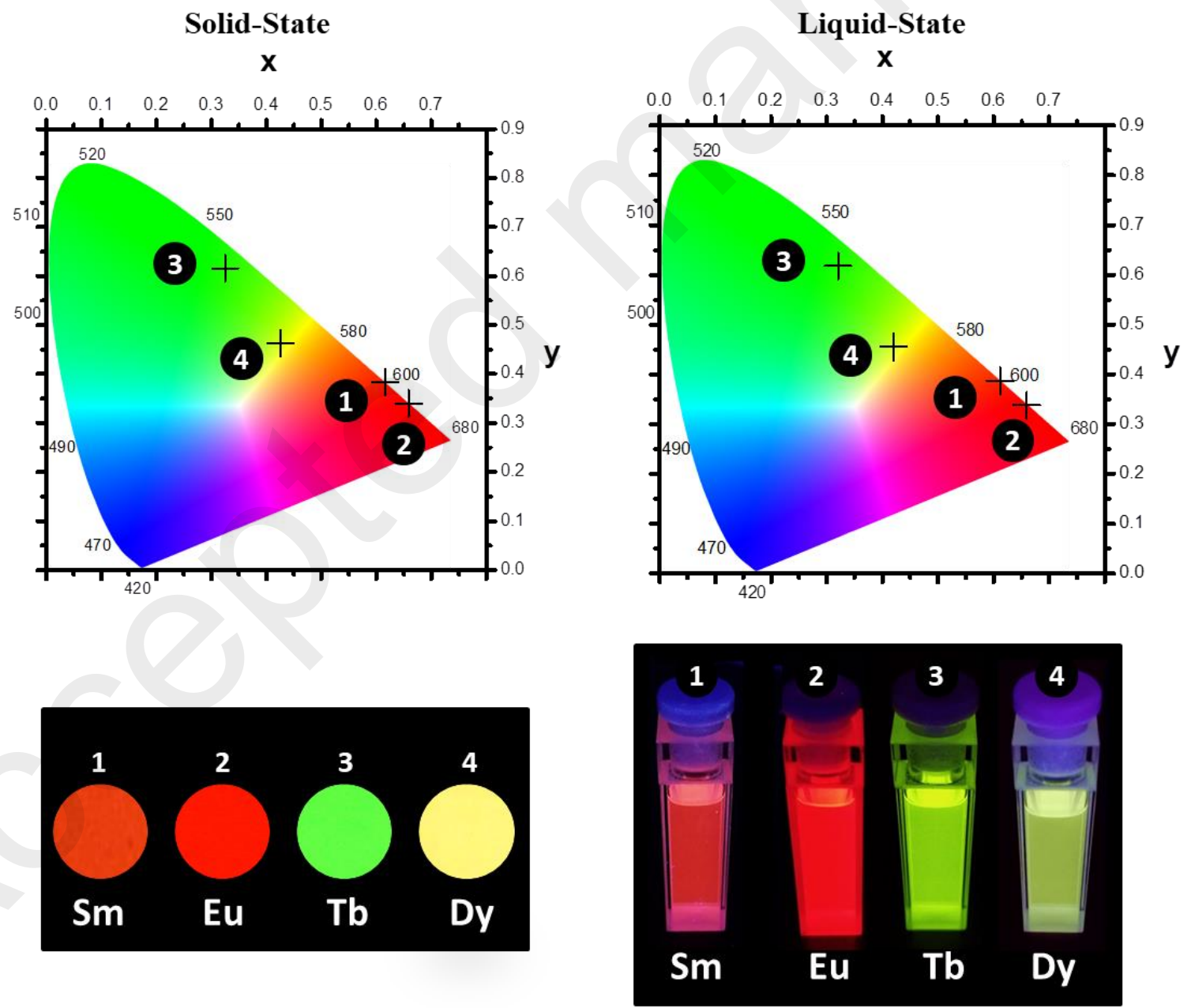

Figure 4. Solid-state (left) and liquid-state (right) colorimetric coordinates $\left(\lambda_{\mathrm{exc}}=303 \mathrm{~nm}\right)$ (top) and picture under UV irradiation $\left(\lambda_{\text {exc }}=312 \mathrm{~nm}\right)$ of $\left[\mathrm{Ln}_{0.2} \mathrm{La}_{1.8}(\mathrm{dcpa})_{3}\left(\mathrm{H}_{2} \mathrm{O}\right)\right]_{\infty}$ powders and $\left[\mathrm{Ln}_{0.2} \mathrm{Laa}_{1.8}(\mathrm{dcpa})_{3}\left(\mathrm{H}_{2} \mathrm{O}\right)\right]_{\infty}: \mathrm{EtOH}\left(0.3{\left.\mathrm{~g} . \mathrm{L}^{-1}\right)}\right.$ suspensions with $\mathrm{Ln}=\mathrm{Sm}, \mathrm{Eu}, \mathrm{Tb}$ and Dy. 
Results reported in Table 1 and Figure 4 show that color emission are perfectly identical in the solid-state and in the liquid-state. The luminances and the overall quantum yields are, as expected, weaker in the liquid-state but still sizeable, especially for the Tb- and Eu-derivatives.

It can also be noticed that the luminescence lifetimes of the $\mathrm{Tb}-, \mathrm{Sm}$ - and Dy-derivatives are longer in the liquid-state than in the solid-state. This is expected because the distances between the grains are longer in the liquid-state than in the solid-state which induces a decreasing of the inter-metallic energy transfers. ${ }^{40}$ On the opposite luminescent lifetime of the Eu-derivative is smaller in the liquid-state than in the solid-state. This could be related to the numerous $\mathrm{O}-\mathrm{H}$ and $\mathrm{C}-\mathrm{H}$ vibrators of the ethanol molecules, that surround the particles, that efficiently quench $\mathrm{Eu}^{3+}$ luminescence. ${ }^{40}$

\section{Color tunable suspensions of molecular alloys: investigation of a family of Ln-CPMAs with two emitting Ln ion}

As evoked in the introduction section, the design of nanometric particles of Ln-CPMAs is very challenging and interesting for some technological applications, such as fight against counterfeiting, for example.

However, if the final target is to obtain a fingerprint in the solid-state, such as for luminescent ink-jet printing, for instance, nanometric particles of Ln-CPMAs are not mandatory. Soluble complexes mixed during the printing can do the job. ${ }^{14,41}$ Indeed, the chemical similarity of the lanthanide ions ${ }^{42}$ will allow the complexes to co-crystallize during the drying process and each grain will contain the whole information. ${ }^{43}$

On the contrary, if the target is to obtain a fingerprint in the liquid-state, such as for tagging technical liquids, the use of nanometric grains of molecular alloys, as we propose here, is mandatory. 
Therefore, the synthesis of series of nanometric Ln-CPMAs is a key point. Thus, we have synthesized a series of compounds with general chemical formula $\left[\mathrm{Eu}_{0.2 x} \mathrm{~Tb}_{0.2-0.2 x} \mathrm{La}_{1.8}(\mathrm{dcpa})_{3}\left(\mathrm{H}_{2} \mathrm{O}\right)\right]_{\infty}$ with $0 \leq x \leq 1$ (Table $\left.\mathrm{S} 5\right)$. Emission spectra and colorimetric coordinates of these compounds, in the solid-state and in suspension in ethanol $\left(0.3\right.$ g.L $\left.{ }^{-1}\right)$ are reported in Figure 5.
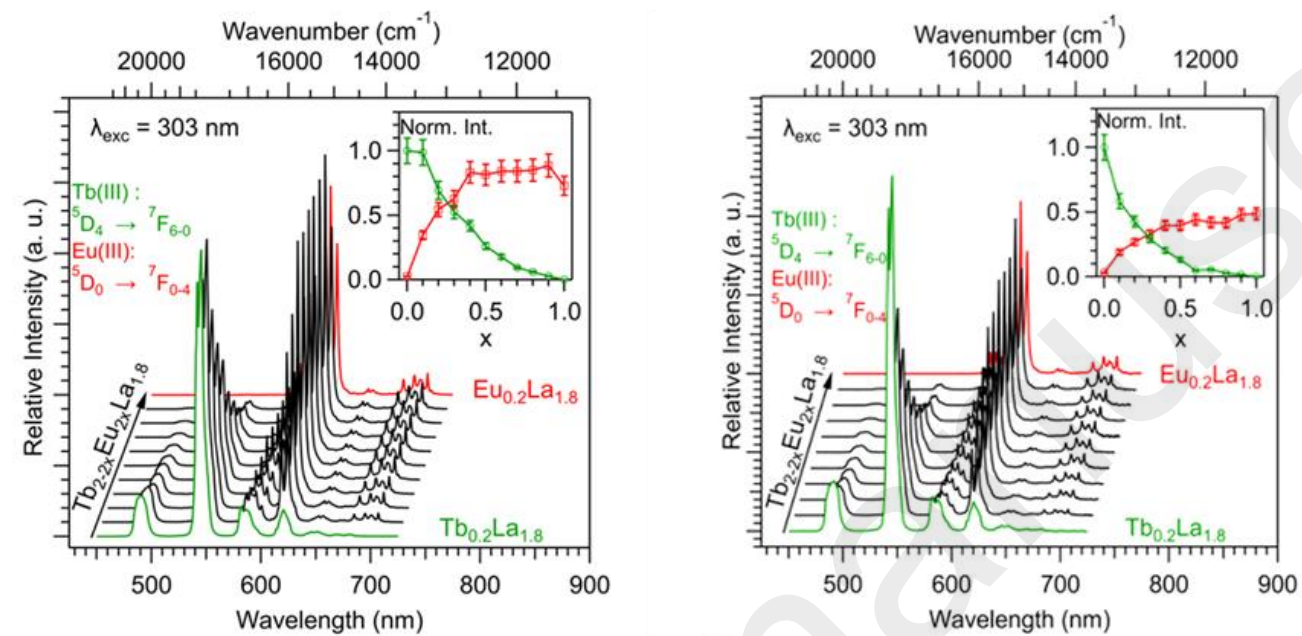

$\mathbf{X}$

$\mathbf{x}$
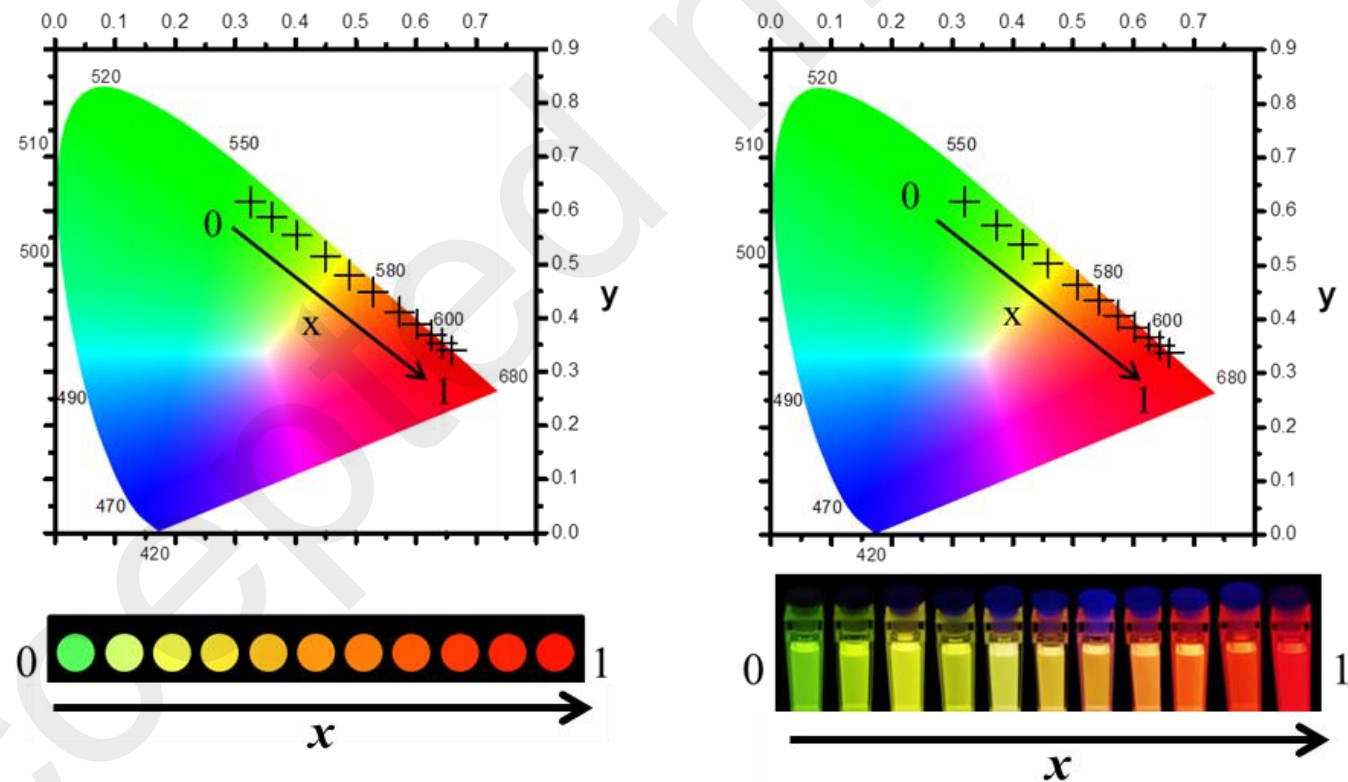

Figure 5. Emission spectra $\left(\lambda_{\mathrm{exc}}=303 \mathrm{~nm}\right)$ (top) (in inset integrated intensities of the major characteristic peaks of $\mathrm{Eu}^{3+}$ and $\left.\mathrm{Tb}^{3+}\right)$, colorimetric coordinates $\left(\lambda_{\operatorname{exc}}=303 \mathrm{~nm}\right)$ (middle) and picture under UV irradiation $\left(\lambda_{\text {exc }}=312 \mathrm{~nm}\right.$ ) (bottom) of $\left[\mathrm{Eu}_{0.2 x} \mathrm{~Tb}_{0.2-0.2 x} \mathrm{La}_{1.8}(\mathrm{dcpa})_{3}\left(\mathrm{H}_{2} \mathrm{O}\right)\right]_{\infty}$ with $0 \leq x \leq 1$ in the solid-state (left) and in suspension in ethanol $\left(0.3 \mathrm{~g} . \mathrm{L}^{-1}\right)$ (right), error bars $=10 \%$. 


\section{Complex optical signatures: investigation of a family of Ln-CPMAs with four emitting Ln}

ion

Figure 5 evidences that the luminescence properties, in the solid-state and in the dispersion, are essentially identical. This clearly indicates that, contrary to a dispersion of a mixture of complexes whose emission color is always dominated by the emission color of the brightest complex, it is possible to finely tune the emission color of a dispersion of Ln-CPMAs. Moreover, luminance for this series of dispersions is sizeable ranging approximately from 12 to $2 \mathrm{~cd} . \mathrm{m}^{-2}\left(\lambda_{\mathrm{exc}}=312 \mathrm{~nm}\right.$; Flux $0.75(2) \mathrm{mW} \cdot \mathrm{m}^{-2}$ ) (Figure S6). To the best of our knowledge, such a high emission associated with such high color tunability has never been reported before and paves the road for technical liquids tagging.

In order to further demonstrate the high potentiality of these materials for elaborated tagging we have studied and compared the luminescence properties, in the solid-state and in the liquid-state, of a penta-lanthanide molecular alloy, $\left[\mathrm{Sm}_{0.07} \mathrm{Eu}_{0.02} \mathrm{~Tb}_{0.04} \mathrm{Dy}_{0.07} \mathrm{La}_{1.8}(\mathrm{dcpa})_{3}\left(\mathrm{H}_{2} \mathrm{O}\right)\right]_{\infty}$ (Table S6), that presents, in the solid-state, ${ }^{33} \mathrm{a}$ very rich and complex emission spectrum (Figure 6). 

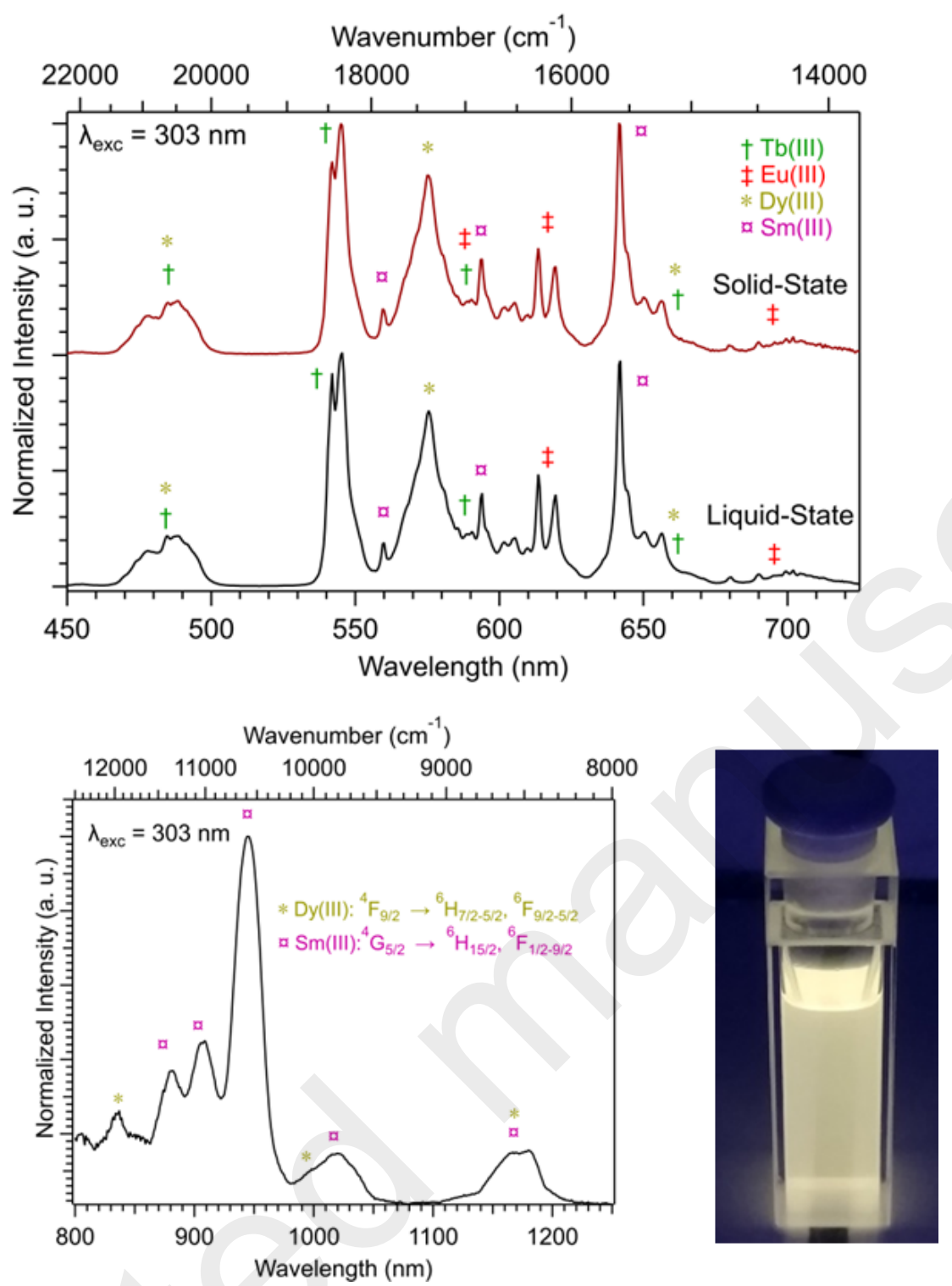

Figure 6. Emission spectra $\left(\lambda_{\text {exc }}=303 \mathrm{~nm}\right)$ of $\left[\mathrm{Sm}_{0.07} \mathrm{Eu}_{0.02} \mathrm{~Tb}_{0.04} \mathrm{Dy}_{0.07} \mathrm{La}_{1.8}(\mathrm{dcpa})_{3}\left(\mathrm{H}_{2} \mathrm{O}\right)\right]_{\infty}$ and $\left[\mathrm{Sm}_{0.07} \mathrm{Eu}_{0.02} \mathrm{~Tb}_{0.04} \mathrm{Dy}_{0.07} \mathrm{La}_{1.8}(\mathrm{dcpa})_{3}\left(\mathrm{H}_{2} \mathrm{O}\right)\right]_{\infty}: \mathrm{EtOH}\left(0.3 \mathrm{~g} . \mathrm{L}^{-1}\right)$ in the visible domain (top) and of $\left[\mathrm{Sm}_{0.07} \mathrm{Eu}_{0.02} \mathrm{~Tb}_{0.04} \mathrm{Dy}_{0.07} \mathrm{La}_{1.8}(\mathrm{dcpa})_{3}\left(\mathrm{H}_{2} \mathrm{O}\right)\right]_{\infty}: \mathrm{EtOH}\left(0.3 \mathrm{~g} . \mathrm{L}^{-1}\right)$ in the IR domain (bottom left). Picture under UV irradiation of a $\left[\mathrm{Sm}_{0.07} \mathrm{Eu}_{0.02} \mathrm{~Tb}_{0.04} \mathrm{Dy}_{0.07} \mathrm{La}_{1.8}(\mathrm{dcpa})_{3}\left(\mathrm{H}_{2} \mathrm{O}\right)\right]_{\infty}: \mathrm{EtOH}$ $\left(0.3\right.$ g.L. $\left.\mathrm{L}^{-1} ; \lambda_{\mathrm{exc}}=312 \mathrm{~nm}\right)$ suspension (bottom right).

As shown in Figure 6, this compound, when dispersed in ethanol, exhibits a sizeable emission in the visible domain $\left(1.40 \mathrm{~cd} . \mathrm{m}^{-2} ; \lambda_{\mathrm{exc}}=312 \mathrm{~nm}\right.$, flux: $\left.0.75(2) \mathrm{mW} . \mathrm{cm}^{-2}\right)$ and its emission spectrum is essentially identical to that recorded in the solid-state. This example shows that this approach can provide white light emission by a judicious choice of the metallic ions in both the solid- and the liquid-states. Moreover this visible emission is combined with sizeable IR emission (Figures 6 and S7).

\section{Thermal and chemical stabilities of the suspensions.}


It has been demonstrated previously that these Ln-CPMAs are stable up to $400^{\circ} \mathrm{C}$ in the solid-state. This allows their use in numerous industrial processes. ${ }^{33}$ In order to estimate the influence of a temperature change on these compounds, we have recorded the emission spectra of a powder of $\left[\mathrm{Tb}_{0.16} \mathrm{Eu}_{0.04} \mathrm{La}_{1.8}(\mathrm{dcpa})_{3}\left(\mathrm{H}_{2} \mathrm{O}\right)\right]_{\infty}$ (Table $\mathrm{S} 7$ ) between $77 \mathrm{~K}$ and $363 \mathrm{~K}$ $\left(\lambda_{\text {exc }}=303 \mathrm{~nm}\right)$. This composition has been chosen because it provides comparable $\mathrm{Eu}^{3+}$ and $\mathrm{Tb}^{3+}$ emission peaks. ${ }^{34}$ (Figure 7).

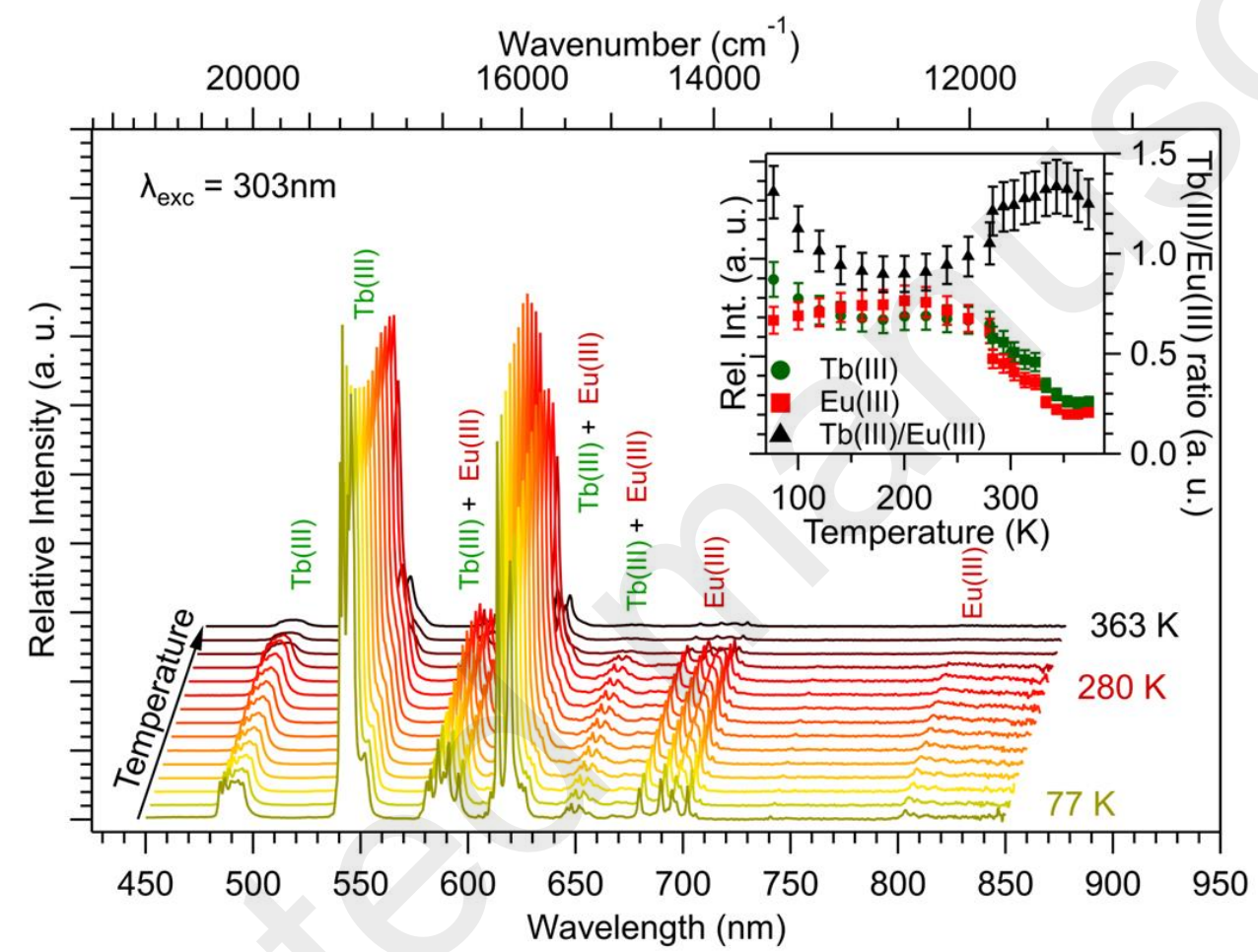

Figure 7. Solid-state emission spectra $\left(\lambda_{\text {exc }}=303 \mathrm{~nm}\right)$ vs temperature between $77 \mathrm{~K}$ and $363 \mathrm{~K}$ of $\left[\mathrm{Tb}_{0.16} \mathrm{Eu}_{0.04} \mathrm{La}_{1.8}(\mathrm{dcpa})_{3}\left(\mathrm{H}_{2} \mathrm{O}\right)\right]_{\infty}$. At $77 \mathrm{~K}, \tau_{\mathrm{obs}}(\mathrm{Eu})=2.04(1) \mathrm{ms}$ and $\tau_{\mathrm{obs}}(\mathrm{Tb})=2.02(1) \mathrm{ms}$. At $293 \mathrm{~K}, \tau_{\mathrm{obs}}(\mathrm{Eu})=1.88(1) \mathrm{ms}$ and $\tau_{\mathrm{obs}}(\mathrm{Tb})=1.78(2) \mathrm{ms}$. In inset, the relative intensities of the major emission peaks of $\mathrm{Tb}^{3+}$ and $\mathrm{Eu}^{3+}$, error bars $=10 \%$.

Figure 7 shows that emission intensities of both optically active lanthanide ions remains essentially unchanged between $77 \mathrm{~K}$ and $280 \mathrm{~K}$ and then decrease quite abruptly until $363 \mathrm{~K}$, because of the increasing of non-radiative de-excitation pathways, but remains sizeable. This indicates that luminescence intensity is sizeable over a quite large temperature range that fit well with the liquid-state temperature range of numerous usual organic solvents. 
If liquids tagging is targeted, the suspension must be stable for quite a long time. Suspensions in ethanol remain limpid to the naked eye and no sedimentation is observed after several weeks. DLS measurement of $\left[\mathrm{Eu}_{0.2} \mathrm{La}_{1.8}(\mathrm{dcpa})_{3}\left(\mathrm{H}_{2} \mathrm{O}\right)\right]_{\infty}: \mathrm{EtOH}\left(0.3 \mathrm{~g} . \mathrm{L}^{-1}\right)$ have been performed just after the preparation of the suspension and one month later. The particle size distributions (Zaverage and PDI) of both measurements are almost identical within the +/- 5\% accuracy of the DLS measurements, (Figures 8 and S8) which strongly suggests that no significant segregation occurs over the period.
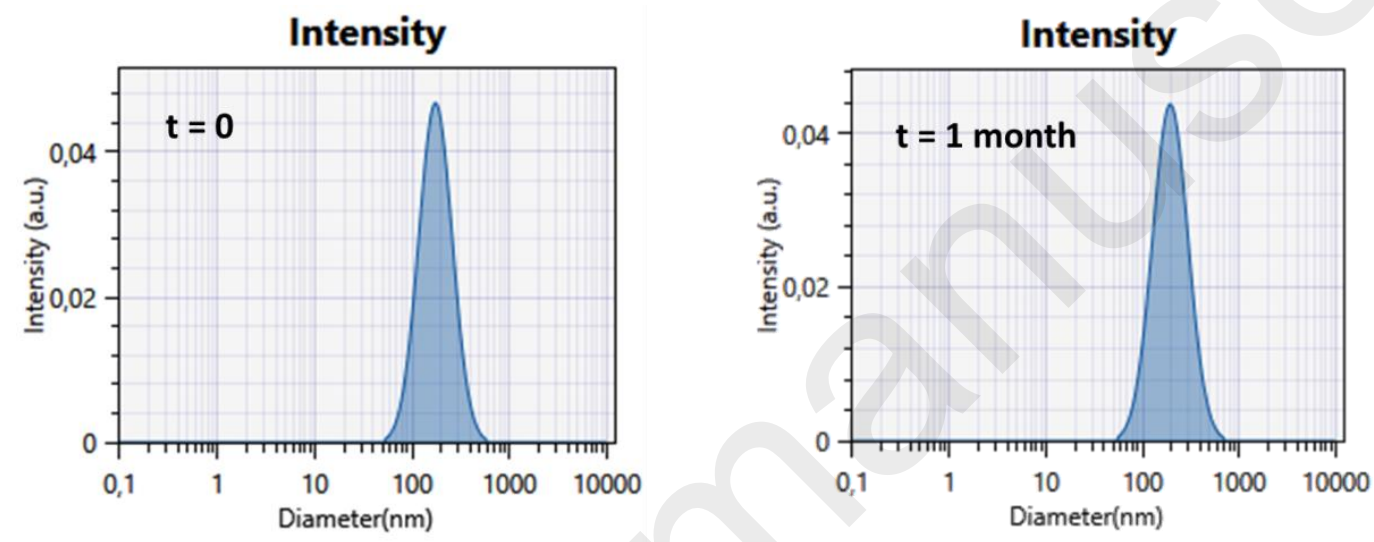

Figure 8. DLS measurements for $\left[\mathrm{Eu}_{0.2} \mathrm{La}_{1.8}(\mathrm{dcpa})_{3}\left(\mathrm{H}_{2} \mathrm{O}\right)\right]_{\infty}: \mathrm{EtOH}\left(0.3 \mathrm{~g} . \mathrm{L}^{-1}\right)$ at $\mathrm{t}=0$ and $\mathrm{t}=1$ month. $\mathrm{Z}$ average $=138 \mathrm{~nm}(+/-5 \%) \mathrm{PDI}=0.17$ (a.u.) and $\mathrm{Z}$ average $=148 \mathrm{~nm}(+/-5 \%)$ $\mathrm{PDI}=0.19$ (a.u.) at $\mathrm{t}=0$ and $\mathrm{t}=1$ month, respectively. Measurement wavelength is $638 \mathrm{~nm}$.

In order to confirm that the suspensions are actually stable over a long period of time, absorption, emission and excitation spectra of $\left[\mathrm{Eu}_{0.2} \mathrm{La}_{1.8}(\mathrm{dcpa})_{3}\left(\mathrm{H}_{2} \mathrm{O}\right)\right]_{\infty}: \mathrm{EtOH}\left(0.3 \mathrm{~g} . \mathrm{L}^{-1}\right)$ have been recorded versus time over a month (Figures 9 and S9). 

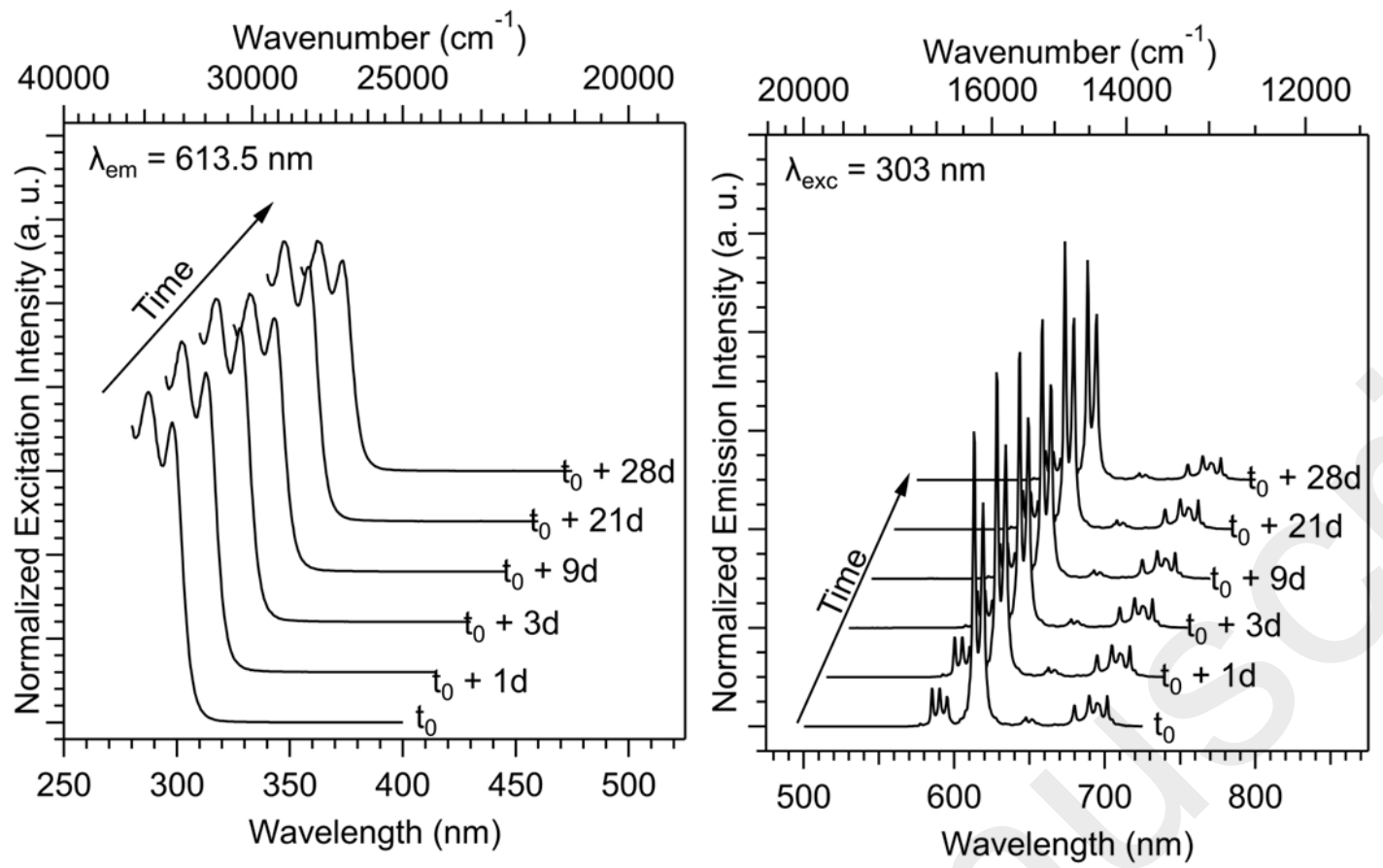

Figure 9. Excitation $\left(\lambda_{\mathrm{em}}=613.5 \mathrm{~nm}\right)$ (left) and emission $\left(\lambda_{\mathrm{exc}}=303 \mathrm{~nm}\right)$ (right) spectra of $\left[\mathrm{Eu}_{0.2} \mathrm{La}_{1.8}(\mathrm{dcpa})_{3}\left(\mathrm{H}_{2} \mathrm{O}\right)\right]_{\infty}: \mathrm{EtOH}\left(0.3 \mathrm{~g} . \mathrm{L}^{-1}\right)$ versus time (in days) over a month.

Absorbance (Figure S8) and excitation and emission (Figure 8) spectra show no significant decrease over the whole investigation time. This indicates that "antenna effect" still governs the Ln-CPMA emission and thus that no de-coordination of the dcpa ${ }^{2-}$ ligand is observed.

\section{CONCLUSIONS AND OUTLOOK.}

In summary, lanthanide-based coordination polymers molecular alloys (Ln-CPMAs) iso-structural with $\left[\mathrm{Eu}_{2}(\mathrm{dcpa})_{3}\left(\mathrm{H}_{2} \mathrm{O}\right)\right]_{\infty}$ constitute, to the best of our knowledge, the first series of Ln-CPMAs that present similar luminescence properties in the solid-state and dispersed in solutions. The small size of the particles in the solid-state as well as the bright luminescence of this family of compounds make them remarkable. Accordingly highly luminescent and color-tunable suspension can be designed via an environmental friendly process (high yield, in water and at ambient temperature and pressure). These suspensions can be used, for instance, for luminescent ink-jet tagging of administrative documents such as diplomas as demonstrated 
on figure 10. We show that the high stability of the suspensions allows for printing complex luminescent logo and QR codes with a standard ink-jet printer using a single cartridge. The high color tunability allows traceability by using a specific color for a given document or academic year for example. We also show that the tagging is extremely luminescent and as bright as the luminescent tagging of a banknote.

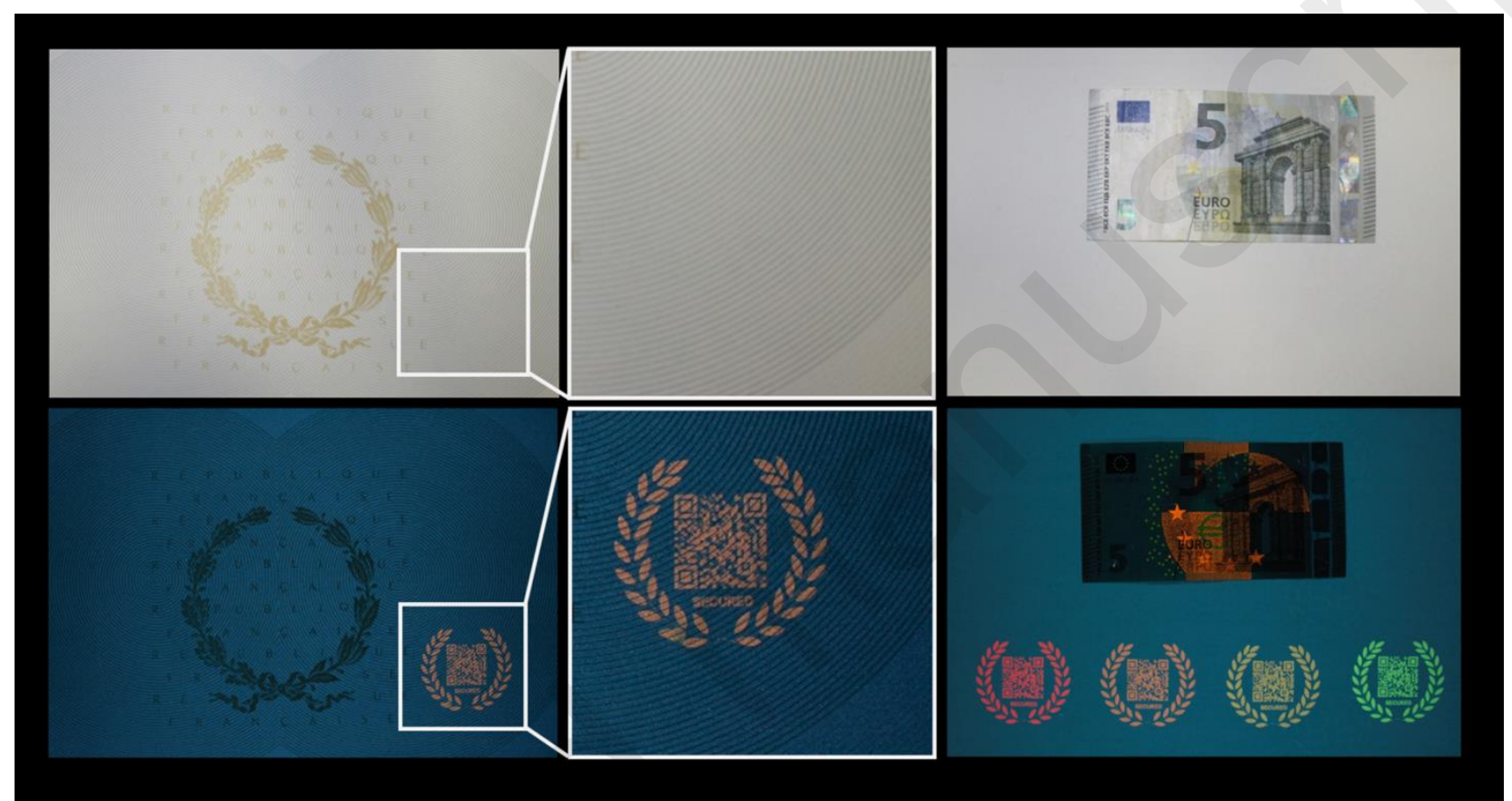

Figure 10. Top: Secured diploma from the National Institute of Applied Sciences of Rennes under day light (left) and UV irradiation $\left(\lambda_{\mathrm{exc}}=312 \mathrm{~nm}\right.$, flux $\left.=0.92 \mathrm{~mW} . \mathrm{cm}^{-2}\right)$ (right). Bottom left: four possible security logos with color emission varying from green to red. Bottom right. Bank note under UV irradiation $\left(\lambda_{\mathrm{exc}}=312 \mathrm{~nm}\right.$, flux $\left.=0.92 \mathrm{~mW} . \mathrm{cm}^{-2}\right)$ for brightness comparison.

These taggants, are also of particular interest for the tagging of technical liquids. Moreover, the high thermal and chemical stabilities of these molecular alloys can allow their use in a wide range of potential applications.

\section{SUPPORTING INFORMATION.}

X-ray powder diffraction, Electron Dispersive Spectroscopy and optical measurements details;

Relative metallic contents measured by EDS of the CPMAs; Experimental powder X-ray 
diffraction pattern of $\left[\mathrm{Eu}_{0.2} \mathrm{La}_{1.8}(\mathrm{dcpa})_{3}\left(\mathrm{H}_{2} \mathrm{O}\right)\right]_{\infty}$; Emission spectra of the colloidal suspensions of $\left[\mathrm{Tb}_{0.2} \mathrm{La}_{1.8}(\mathrm{dcpa})_{3}\left(\mathrm{H}_{2} \mathrm{O}\right)\right]_{\infty}$ in various solvent; Experimental powder X-ray diffraction patterns of the solids obtained after evaporation of the solvents of the colloidal suspensions of $\left[\mathrm{Tb}_{0.2} \mathrm{La}_{1.8}(\mathrm{dcpa})_{3}\left(\mathrm{H}_{2} \mathrm{O}\right)\right]_{\infty} ;$ Emission spectra of the aqueous colloidal suspensions of $\left[\mathrm{Tb}_{0.2} \mathrm{La}_{1.8}(\mathrm{dcpa})_{3}\left(\mathrm{H}_{2} \mathrm{O}\right)\right]_{\infty}$ in water $v s \mathrm{pH}$; Experimental powder X-ray diffraction patterns of the solids obtained after evaporation of the water of the colloidal suspensions of $\left[\mathrm{Tb}_{0.2} \mathrm{La}_{1.8}(\mathrm{dcpa})_{3}\left(\mathrm{H}_{2} \mathrm{O}\right)\right]_{\infty}$ vs $\mathrm{pH} ;$ Luminance versus $x$ of colloidal suspensions of $\left[\mathrm{Eu}_{0.2 x} \mathrm{~Tb}_{0.2-0.2 x} \mathrm{La}_{1.8}(\mathrm{dcpa})_{3}\left(\mathrm{H}_{2} \mathrm{O}\right)\right]_{\infty}: \mathrm{EtOH}\left(0.3 \mathrm{~g} . \mathrm{L}^{-1}\right)$ with $0 \leq x \leq 1$; Emission spectra of $\left[\mathrm{Sm}_{0.07} \mathrm{Eu}_{0.02} \mathrm{~Tb}_{0.04} \mathrm{Dy}_{0.07} \mathrm{La}_{1.8}(\mathrm{dcpa})_{3}\left(\mathrm{H}_{2} \mathrm{O}\right)\right]_{\infty}$ and $\left[\mathrm{Sm}_{0.07} \mathrm{Eu}_{0.02} \mathrm{~Tb}_{0.04} \mathrm{Dy}_{0.07} \mathrm{La}_{1.8}(\mathrm{dcpa})_{3}\left(\mathrm{H}_{2} \mathrm{O}\right)\right]_{\infty}: \mathrm{EtOH}\left(0.3 \mathrm{~g} . \mathrm{L}^{-1}\right)$ in the IR domain; Best fits of the DLS measurements for $\left[\mathrm{Eu}_{0.2} \mathrm{La}_{1.8}(\mathrm{dcpa})_{3}\left(\mathrm{H}_{2} \mathrm{O}\right)\right]_{\infty}: \mathrm{EtOH}\left(0.3 \mathrm{~g} \cdot \mathrm{L}^{-1}\right)$ at $\mathrm{t}=0$ and $\mathrm{t}=1$ month with Cumulants algorithm; Absorbance versus time of colloidal suspensions of $\left[\mathrm{Eu}_{0.2} \mathrm{La}_{1.8}(\mathrm{dcpa})_{3}\left(\mathrm{H}_{2} \mathrm{O}\right)\right]_{\infty}: \mathrm{EtOH}\left(0.3 \mathrm{~g} . \mathrm{L}^{-1}\right)$ between 290 and $500 \mathrm{~nm}$.

\section{ACKNOWLEDGEMENTS.}

Special thanks to Cordouan Technologies Company for achieving DLS measurements and for their expertise in nano-particle size measurement of colloidal suspensions. The CMEBA (centre de microscopie à balayage et microanalyse) is acknowledged for SEM pictures. 


\section{REFERENCES}

1. J. C. G. Bünzli, Rising stars in science and technology : Luminescent lanthanide materials. Eur. J. Inorg. Chem. 2017, 5058-5063.

2. J. C. G. Bünzli; S. V. Eliseeva, Intriguing aspect of lanthanide luminescence. Chem. Sci. 2013, 4, 1039-1049.

3. Y. Cui; J. Zhang; H. He; G. Qian, Photonic functional metal-organic frameworks. Chem. Soc. Rev. 2018, 47, 5740-5785.

4. Y. Cui; B. Li; H. He; W. Zhou; B. Chen; G. Qian, Metal-organic frameworks as platforms for functionnal materials. Accounts Chem. Res. 2016, 49, 483-493.

5. Y. Cui; J. Zhang; B. Chen; G. Qian, Lanthanide Metal-Organic Frameworks for Luminescent Applications. Handbook on the Physics and Chemistry of Rare Earths 2016, 50, 243-268.

6. D. S. C. Brites; A. Millan; L. D. Carlos, Lanthanides in Luminescent Thermometry. In Handbook on the Physics and Chemistry of Rare Earths, Gschneidner, K. A.; Bünzli, J. C. G.; Pecharsky, V. K., Eds. Elsevier: 2016; Vol. 49, p 339-427.

7. J. Rocha; D. S. C. Brites; L. D. Carlos, Lanthanide organic framework luminescent thermometers. Chem. - Eur. J. 2016, 22, 14782-14795.

8. Y. Cui; Y. Yue; G. Qian; B. Chen, Luminescent Functional Metal-Organic Frameworks. Chem. Rev. 2012, 1126-1162.

9. M. Pan; W.-M. Liao; S.-Y. Yin; S.-S. Sun; C.-Y. Su, Single-Phase White-Light-Emitting and Photoluminescent Color-Tuning Coordination Assemblies. Chemical Reviews 2018, 118, 8889-8935.

10. J.-C. G. Bünzli, Lanthanide luminescence for biomedical analyses and imaging. Chem. Rev. 2010, 111, 2729-2755.

11. K.-M. Wang; L. Du; Y.-L. Ma; J.-S. Zhao; Q. Wang; T. Yan; Q.-H. Zhao, Multifunctionnal chemical sensors and luminescent thermometers based on lanthanide metal-organic framework materials. Cryst. Eng. Comm. 2016, 18, 2690-2700.

12. O. Guillou; C. Daiguebonne; G. Calvez; K. Bernot, A long journey in lanthanide chemistry : from fundamental crystallogenesis studies to commercial anti-counterfeiting taggants. Accounts Chem. Res. 2016, 49, 844-856.

13. K. A. White; D. A. Chengelis; K. A. Gogick; J. Stehman; N. L. Rosi; S. Petoud, Near infra-red luminescent lanthanide MOF barcodes. J. Am. Chem. Soc. 2009, 131, 18069-18071.

14. J. Andres; R. D. Hersch; J. E. Moser; A. S. Chauvin, A new counterfeiting feature relying on invisible luminescent full color images printed with lanthanide-based Inks. Adv. Func. Mater. 2014, 24, 5029-5036.

15. Y.-C. Chen; J.-L. Liu; M.-L. Tong, 4f-Clusters for Cryogenic Magnetic Cooling. Springer Berlin Heidelberg: Berlin, Heidelberg, 2015, 10.1007/430_2015_5001p 1-19.

16. P. Dechambenoit; S. Ferlay; N. Kyritsakas; M. W. Hosseini, Playing with isostructurality : from tectons to molecular alloys and composite crystals. Chem. Comm. 2009, 1559-1561.

17. I. Badiane; S. Freslon; Y. Suffren; C. Daiguebonne; G. Calvez; K. Bernot; M. Camara; O. Guillou, High britness and easy color modulation in lanthanide-based coordination polymers with 5methoxyisophthalate as ligand: Toward emission colors additive strategy. Cryst. Growth Des. 2017, 17, 1224-1234.

18. S. Freslon; Y. Luo; C. Daiguebonne; G. Calvez; K. Bernot; O. Guillou, Brightness and color tuning in a series of lanthanide-based coordination polymers with benzene 1,2,4,5-tetracarboxylic acid as ligand. Inorg. Chem. 2016, 55, 794-802.

19. Y. Luo; K. Bernot; G. Calvez; S. Freslon; C. Daiguebonne; O. Guillou; N. Kerbellec; T. Roisnel, 1,2,4,5-benzene-tetra-carboxylic acid : A versatile ligand for high dimensionnal lanthanide-based coordination polymers. Cryst. Eng. Comm. 2013, 15, 1882-1896.

20. V. Haquin; M. Etienne; C. Daiguebonne; S. Freslon; G. Calvez; K. Bernot; L. Le Polles; S. E. Ashbrook; M. R. Mitchell; J. C. G. Bünzli; O. Guillou, Color and brightness tuning in hetero-nuclear lanthanide teraphthalate coordination polymers. Eur. J. Inorg. Chem. 2013, 3464-3476. 
21. B. Seoane; S. Castellanos; A. Dikhtiarenko; F. Kapteijn; J. Gascon, Multi-scale crystal engineering of metal organic frameworks. Coord. Chem. Rev. 2016, 307, 147-187.

22. V. Valtchev; L. Tosheva, Porous Nanosized Particles: Preparation, Properties, and Applications. Chemical Reviews 2013, 113, 6734-6760.

23. N. A. Khan; S. H. Jhung, Synthesis of metal-organic frameworks (MOFs) with microwave or ultrasound: Rapid reaction, phase-selectivity, and size reduction. Coord. Chem. Rev. 2015, 285, 11-23. 24. Q. Evrard; F. Houard; C. Daiguebonne; G. Calvez; Y. Suffren; O. Guillou; M. Mannini; K. Bernot, Sonocrystallization as an Efficient Way to Control the Size, Morphology, and Purity of Coordination Compound Microcrystallites: Application to a Single-Chain Magnet. Inorg. Chem. 2020, 59, 9215-9226. 25. Y. Lu; B. Yan, Luminescent lanthanide barcodes based on postsynthetic modified nanoscale metal-organic frameworks. J. Mater. Chem. C 2014, 2, 7411-7416.

26. C. Neaime; C. Daiguebonne; G. Calvez; S. Freslon; K. Bernot; F. Grasset; S. Cordier; O. Guillou, Nanometrization of Lanthanide-Based Coordination Polymers. Chem. - Eur. J. 2015, 21, 17466-17473.

27. C. Daiguebonne; N. Kerbellec; O. Guillou; J. C. G. Bünzli; F. Gumy; L. Catala; T. Mallah; N. Audebrand; Y. Gérault; K. Bernot; G. Calvez, Structural and luminescent properties of micro-sized and nano-sized particles of lanthanide terephthalate coordination polymers. Inorg. Chem. 2008, 47, 37003708

28. N. Kerbellec; L. Catala; C. Daiguebonne; A. Gloter; O. Stephan; J. C. G. Bünzli; O. Guillou; T. Mallah, Luminescent Coordination Nanoparticles. New J. Chem. 2008, 32, 584-587.

29. K. Fan; X. Wang; Y.-L. Ma; Y. Li; G. Han; Z. Yin; J. L. Song, Water-soluble lanthanide coordination polymers particles with white-light emission and color tuning. RSC Advances 2019, 9, 32137-32140.

30. Y.-M. Wang; X.-T. Tian; H. Zhang; Z.-R. Yang; X.-B. Yin, Anticounterfeiting quick response code with emission color of invisible Metal-Organic Frameworks as encoding information. ACS Appl. Mater. Interfaces 2018, 10, 22445-22452.

31. H. He; S.-H. Chen; D.-Y. Zhang; R. Hao; C. Zhang; E.-C. Yang; X.-J. Zhao, A micrometer-sized europium(III)-organic framework for selective sensing of the $\mathrm{Cr}_{207^{2-}}$ anion and picric acid in water systems. Dalton Trans. 2017, 46, 13502-13509.

32. Y.-H. Qiao; S.-H. Chen; S. Xu; E. C. Yang; X.-J. Zhao, 4,5-dichlorophthalate-extended lanthanide coordination polymers with layer and ribbon motifs: synthesis, structure, and luminescence. $Z$. Anorg. Allg. Chem. 2018, 644, 1108-114.

33. Y. Pointel; Y. Suffren; C. Daiguebonne; F. Le Natur; S. Freslon; G. Calvez; K. Bernot; O. Guillou, Rational design of dual IR and visible highly luminescent light lanthanides based coordination polymers. Inorg. Chem. 2020, 59, 10673-10687.

34. Y. Pointel; F. Houard; Y. Suffren; C. Daiguebonne; F. Le Natur; S. Freslon; G. Calvez; K. Bernot; O. Guillou, High luminance of hetero lanthanide based molecular alloys by phase-induction strategy. Inorg. Chem. 2020, 59, 11028-11040.

35. P. T. Anastas; J. C. Warner, Green Chemistry : Theory and Practice. Oxford University Press Inc.: New-York, 2000.

36. A. M. Badiane; S. Freslon; C. Daiguebonne; Y. Suffren; K. Bernot; G. Calvez; K. Costuas; M. Camara; O. Guillou, Lanthanide based coordination polymers with a 4,5-dichlorophthalate ligand exhibiting highly tunable luminescence : Toward luminescent bar codes. Inorg. Chem. 2018, 57, 33993410 .

37. S. Dang; X. Min; W. Yang; F. Y. Yi; H. You; Z. M. Sun, Lanthanide metal-organic frameworks showing luminescence in the visible and near infrared regions with potential for acetone sensing. Chem. - Eur. J. 2013, 19, 17172-17179.

38. N. Lewinski; V. Colvin; R. Derezek, Cytotoxicity of Nanoparticles. Small 2008, 4, 26-49.

39. S. I. Weissman, Intramolecular energy transfer - The fluorescence of complexes of europium. J. Chem Phys 1942, 10, 214-217.

40. J. C. G. Bünzli; S. V. Eliseeva, Basics of lanthanide photophysics. In Lanthanide Luminescence, Hänninen, P.; Härmä, H., Eds. Springer Berlin Heidelberg: 2010; Vol. 7, p 1-45. 
41. V. V. Utochnikova; A. Grishko; A. Vashchenko; A. Goloveshkin; A. Averin; N. Kuzmina, Lanthanide Tetrafluoroterephthalates for Luminescent Ink-Jet Printing. Eur. J. Inorg. Chem. 2017, 56355639.

42. D. G. Karraker, Coordination of trivalent lanthanide ions. J. Chem. Educ. 1970, 47, 424-430.

43. R. Maouche; S. Belaid; B. Benmerad; S. Bouacida; S. Freslon; C. Daiguebonne; Y. Suffren; G. Calvez; K. Bernot; C. Roiland; L. Le Polles; O. Guillou, Luminescence properties of lanthanide complexes-based molecular alloys. Inorg. Chim. Acta 2020, 501, 119309. 


\section{GRAPHICAL ABSTRACT.}

A series of lanthanides-based coordination polymers molecular alloys colloidal dispersions usable for ink-jet printing and tagging of technical liquids.

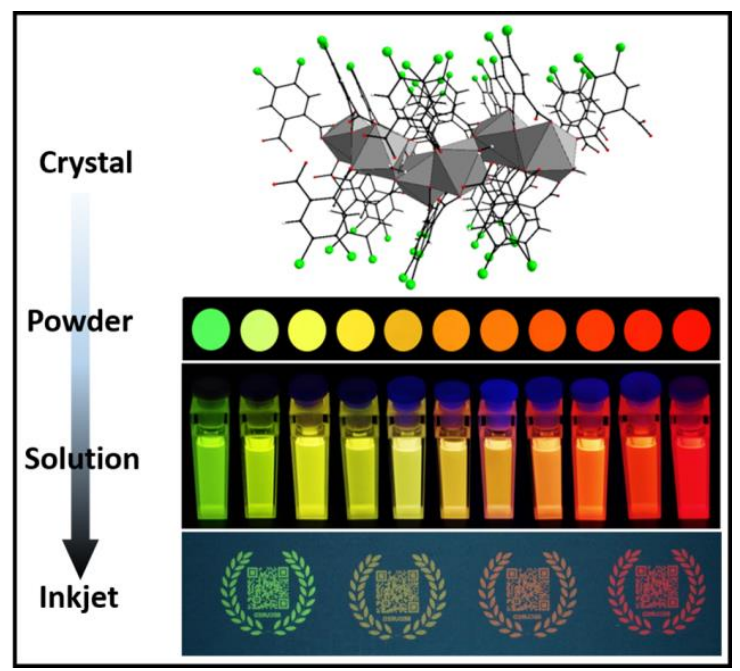

